\title{
Pharmaceutical Applications of Plasticized Polymers
}

\author{
Eva Snejdrova and Milan Dittrich \\ Faculty of Pharmacy, Charles University in Prague \\ Czech Republic
}

\section{Introduction}

The modern pharmaceutical technology is not conceivable without plasticized polymers. The pharmaceutical applications of polymers range from packaging materials or auxiliary substances in conventional dosage forms to membranes or matrices modifying and controlling the drug release characteristics in therapeutic systems. Recently, a great variety of plasticized polymeric systems have been studied as microparticles, matrices, free membranes, membranes for transdermal systems and in situ forming implants. Not only the polymer itself but thorough choice of other ingredients of the polymer system is necessary for required quality of drug delivery system. The plasticizer has the unsubstitutable place in drug polymer system due to its primary role, i. e. improve the flexibility and processability of polymers by lowering the glass transition temperature. The supramolecular structure and relevant properties of specific plasticized polymer drug delivery systems has attracted the interest of many researchers.

\section{Plasticized polymers used as coatings of the dosage forms}

It is common practice to coat oral solid dosage forms with polymeric materials for several purposes, such as modifying drug release, affording gastroprotection, protecting from environmental agents, masking unpleasant taste or just enhancing product aesthetics. A film coating is defined as a thin and uniform polymer based-layer of about 20 to $100 \mu \mathrm{m}$ in thickness, which is applied to the surface of substrates such as tablets, granules, powders, capsules, particles or pellets (Porter, 1995).

Polymers used in coating can be categorized into two types: (i) non-functional or conventional film coating polymers for immediate release coatings; which improve the appearance, the handling, prevent dusting or (ii) functional coating polymers, which can be used to modify the pharmaceutical function of the dosage forms, and include the delayed release dosage forms and sustained release (or extended or prolonged) dosage forms.

Coating films can be usually prepared from organic solvent-based polymers or aqueous solvent-based latex dispersions. However, the aqueous film coating have been favoured in coating technology because of its wide applications, low environmental concerns, efficiency of the process, and wide commercial availability of coating materials. The cellulose ethers and esters are the major group of polymers used in the film coating process. The 
pharmaceutical compositions of two kinds of coated beads were patented. The polymer coatings of the beads differed in water solubility. This pharmaceutical composition comprised phtalates, trimellitates, adipates, sebacates, glycols, polyethers and alkyl citrates as the plasticizers (Paborji \& Flugel 2011).

Cellulose acetate phthalate (CAP), widely used in enteric film coating, is available as a white powder or also as a $30 \%$ solid nanodispersion (pseudolatex) (Aquacoat ${ }^{\circledR}$ CPD). Polyvinyl acetate phthalate is less susceptible to hydrolysis, which minimizes or limits the content of free phthalic acid and other free acids.

Cellulose acetate trimellitate (CAT) has three carboxylic groups on the aromatic ring and dissolves at a $\mathrm{pH}$ of 5.5. The plasticizers as triacetin, acetylated monoglyceride, diethyl phthalate are recommended, and to obtain the best enteric coating results from aqueous processing, ammoniated solutions of CAT in water are the best choice.

Hydroxypropyl methylcellulose phthalate (HPMCP) characteristics, particularly at the $\mathrm{pH}$ where dissolution occurs, are determined by the degree of substitution of the three kinds of substituent groups (i.e. methoxy, hydroxypropoxy, and carboxybenzoyl). Valuable plasticizers include triacetin, acetylated monoglyceride and diethyl phthalate.

Acrylic polymers as a group of various synthetic polymers, methacrylic amino ester copolymers, have diverse functionality in film coating. They can be used for rapidly disintegrating coatings, taste and odour masking, coloured or transparent coatings, etc., and are available mainly as the Eudragit ${ }^{\circledR}$ products.

Methacrylic acid copolymers contain free carboxylic acid groups, and therefore can be used for enteric coating purposes by forming salts with alkalis. Methacrylic acid copolymers are soluble at $\mathrm{pH}$ values higher than 5.5. The addition of a plasticizer in these polymers is necessary. Methacrylic acid copolymers are available as various grades of Eudragit ${ }^{\circledR}$ products.

\subsection{The role of the plasticizer in the film coating}

The plasticizer plays the major role in the all process of the oral dosage form coating, and significantly influences the quality of the coatings, particularly the release of incorporated drugs.

\subsubsection{Film formation facilitated by plasticizer}

The film-formation mechanism from the coating dispersions is a complex process influenced mainly with the type and also with the quantity of plasticizer. The temperature below which a coating will not form a continuous, cohesive film is called the minimum film forming temperature; it is the minimum temperature above the $\mathrm{T}_{\mathrm{g}}$ of the polymer. In order to ensure the optimum conditions for film formation, the really used coating temperature during the application process should be $10-20{ }^{\circ} \mathrm{C}$ above the minimum film forming temperature (Lehmann, 1992). Since plasticizer addition to film coating formulation reduces the $\mathrm{T}_{\mathrm{g}}$ of the polymer, as a result the temperature required for film coating is reduced by plasticization (Zhu et al., 2002). 
A sufficient amount of time should be allowed for the plasticizer uptake to ensure a homogeneous distribution of the plasticizer in the coating film. The time between the addition of the plasticizer to the polymer dispersion and the coating step is usually called as the plasticization time and presents a critical process variable, especially when waterinsoluble plasticizers are used. Water insoluble plasticizers have to be emulsified in the aqueous phase of the polymer dispersions. During plasticization of the polymer dispersions, the plasticizer partitions into the colloidal polymer particles and softens them thus promoting particle deformation and coalescence into a film upon drying. Commercial suppliers of polymer dispersions often recommend a relatively short plasticization time of 30 - 60 minutes irrespective of the solubility of the plasticizer. Plasticizers are incorporated in the amorphous parts of polymers while the structure and size of any crystalline part remains unaffected (Fedorko et al., 2003). The thermal treatment following the application of the coat is known as curing. During this stage of coating, the coated dosage form is subjected to temperatures higher than the $T_{g}$, which facilitates uniform distribution of plasticizers. During curing of the coatings, plasticizers could also redistribute in the polymeric film.

Controlled released pharmaceutical formulations comprising pseudoephedrine embedded in core and coating shell made from mixture of two different polymers were approved. One of the used polymers was water soluble, the second one water insoluble. The water insoluble plasticizer ranged from 0.1 to $15.0 \%$ by weight in this composition (Nair et al., 2010).

\subsubsection{Mechanical properties of the coating improved by plasticizer}

Good flexibility of the coating is essential for insuring the resistance of the coating to the mechanical impact force expected during the coating process, and in the application place of the coated dosage form (particularly in the gastrointestinal tract). However, pure polymer coatings are often brittle. An addition of an external plasticizer to the polymeric networks will increase the flexibility of the coatings (Siepmann et al., 1999).

The affirmative effect of the plasticizers on mechanical properties of the coating is caused by reducing of the cohesive intermolecular forces along the polymer chains. The flexibility is enhanced by increasing strain elongation and decreasing tensile strength and elastic modulus of the polymer (Gutierrez-Rocca \& McGinity, 1994).

For example, triethyl citrate, triacetin and acetyltriethyl citrate used as a water-soluble plasticizer of the hydroxypropylmethylcellulose acetate succinate in press-coated tablets for colon targeting formulation ensure the plastic deformation property of the outer shell due to some interaction between hydroxypropylmethylcellulose acetate succinate and triethyl citrate (Fukui et al., 2001). Plasticized polymeric coating with dispersed bioactive antiinflammatory and anti-thrombogenic drugs was applied for stents (Udipi \& Cheng, 2004).

\subsubsection{Adhesion of coating influenced by plasticizer}

Good adhesion between a polymer and the surface of a solid is a major prerequisite for the film coating of pharmaceutical dosage forms. Loss of adhesion may reduce the functions that the film-coating provides to the solid substrate, particularly the mechanical protection that the coating ensures to the solid substrate and the drug release modified by coating. 
There are two substantial forces which influence the polymer adhesion: the strength of the interfacial bonds between the polymeric film and the surface of the solid, and the internal stresses within the film coating. The interfacial bonding between the tablet surface and polymer coating is made primarily with hydrogen bonds, to a lesser extent with dipoledipole and dipole-induced dipole interactions. The addition of plasticizing agents to coating formulations generally decreases the internal stress in the film by decreasing both the elastic modulus and the glass transition temperature of the film coating (Johnson \& Hathaway, 1991; Rowe, 1981, 1992).

The measured force of adhesion, therefore, would be expected to increase with increased plasticization of the polymer. The contradictory results may be due to the interaction of the plasticizing agent with the polar groups of the polymer within the film structure (Felton \& McGinity, 1999).

The adhesive property of Eudragit films is effected with organic esters used as plasticizers (triacetin, diethyl phthalate, dibutyl phthalate and tributyl citrate were tested). The molecular weight and solubility parameters of the plasticizer seemed to play an important role in changing the adhesive strength of the Eudragit films. The adhesion of Eudragit films is markedly increased when the concentration of the plasticizer is greater than $25 \%$. Tributyl citrate may be the best choice of the plasticizer for the Eudragit film, particularly for the Eudragit E film.

The molecular weight and solubility parameters of the plasticizer seemed to play an important role in changing the adhesive strength of the Eudragit films (Lina et al., 2000).

The water soluble plasticizers, triethyl citrate and polyethylene glycol 6000, lower the $\mathrm{Tg}$ of the films to a greater extent than the hydrophobic plasticizers, tributyl citrate and dibutyl sebacate, and the coatings with the hydrophilic plasticizers exhibit stronger adhesion (Entwistle \& Rowe, 1979; Felton \& McGinity, 1997).

The study of the influence of plasticizers on the adhesion of the acrylic polymer to either hydrophilic or hydrophobic tablet compacts revealed that increasing tablet hydrophobicity decreased adhesion of both cellulosic and acrylic polymers (Felton \& McGinity, 1996, 1997; Rowe, 1977).

\subsection{Factors negatively influencing the coating}

Polymer-plasticizer incompatibility, plasticizer migration out of polymer (and particularly leaching of plasticizer) as well sticking and aging of the film coated dosage influence not only the mechanical properties, but also drug release (Amighi \& Moes, 1996; Arwidsson et al., 1991; Bodmeier \& Paeratakul, 1992; Skultety \& Sims, 1987). For example, dibutyl sebacate unlike triethyl citrate was found to remain within the polymeric coating upon exposure to the dissolution media and thus mechanical properties of coatings during drug release are maintained. Leaching of triethyl citrate out of the film resulting in decreased mechanical resistances facilitates crack formation.

A blend of polymers can be used in the coating of solid dosage forms, and then the type of plasticizer must be chosen responsibly to ensure good quality of the coating. If the plasticizer has different affinities to the individual polymers forming the blend, the 
plasticizer redistribution within the polymeric system during coating occurs. As an example can serve pellets coated with blends of ethyl cellulose and Eudragit ${ }^{\circledR}$ L. Dibutyl sebacate used as plasticizer of this coating shows a higher affinity to ethyl cellulose than to Eudragit ${ }^{\circledR}$ L (Lecomte et. al., 2004).

\section{Free membranes}

A membrane can be in the form of a free film containing the active ingredient, or it can form the outer wall of the body which is its reservoir together with other excipients. The membrane has a defined thickness; it can be porous or compact, it can contain, in addition to the active ingredient, various excipients including plasticizers. In the case of dosage forms such as buccal and sublingual films, capsules intended for oral, rectal or vaginal administration, and inserts placed into cavities, their membranes and membrane systems possess the function of (1) the primary coating increasing stability and enabling administration, (2) separation from and protection against the influence of the biological environment after administration, or (3) controlled release.

Ethyl cellulose films of standard thickness were prepared by slow evaporation of the solvent from chloroform solutions of a $48.8 \%$ ethoxylated cellulose derivative and three plasticizers: classic dibutyl sebacate, vitamin D3 and vitamin E. The individual plasticizers were used in nine different concentrations up to $80 \%$. It has been demonstrated that primarily atocopherol (vitamin E) in concentrations of 40 to $50 \%$ is an advantageous and effective plasticizer of ethyl cellulose from the standpoint of toxicity, ultimate strength, toughness, and Young modulus (Kangarlou et al., 2008). Ethyl cellulose of the identical parameters was employed in the preparation of films using the same method, diethyl sebacate in a $40 \%$ concentration being used as the plasticizer. Chloroform was evaporated using the standard very slow evaporation procedure. A suitable velocity of stress action was found for the most conclusive stress-strain deformation diagrams (Sogol \& Ismaeil, 2011).

Thin films made of poly(lactide-co-glycolide) were prepared from a dichloromethane solution with additions of $15 \%, 25 \%$, or $50 \%$ polyethylene glycol 8000 and 35000 , yielding potential implants of $40 \mu \mathrm{m}$ in thickness containing the antitumor drug paclitaxel. Raman spectrometry was used to demonstrate partial separation of the plasticizer (Steele et al., 2011).

Soft gelatin capsules were formed by a wall of varying thickness containing about 40 to $45 \%$ of gelatin, which is plasticized with water 20 to $30 \%$ and glycerol, or sorbitol 30 to $35 \%$ (Marques et al., 2009). The plasticizer increased the flexibility of gelatin, with increasing concentration to $45 \%$ it decreased the sensitivity to humidity, decreased the tendency to recrystallization, decreased tensile strength and the elastic modulus, increases elongation at break (Bergo \& Sobral, 2007).

Protein films possess good mechanical properties, but they are very sensitive to atmospheric humidity. Their hygroscopic character can be decreased by adding a hydrophobic plasticizer. Esters derived from citric acid such as triethyl citrate, tributyl citrate, acetyl triethyl citrate and acetyl tributyl citrate were tested in various concentrations (Andreuccetti et al., 2009). Their limited miscibility with an aqueous solution of gelatin was solved by 
emulsification of plasticizers with soya lecithin. The tensile stress of the material was decreased with increasing concentrations of the plasticizer, permeability of water vapours was moderately increased.

Biodegradable films were prepared from a protein isolated from sunflower oil with additions of various polyalcohols, such as glycerol, ethylene glycol, propylene glycol, polyethylene glycols. The mixture was subjected to thermo-moulding at $150{ }^{\circ} \mathrm{C}$ using $150 \mathrm{MPa}$. Tensile strength of films was 6.3 to $9.6 \mathrm{MPa}$ and elongation at break was 23 to $140 \%$. Permeability of water vapours was low; films were resistant against aqueous environment only in a limited degree, as migration of the plasticizer took place (Orliac et al., 2003). The plasticizers used were evaluated as suitable for protein films.

\section{Polymeric membranes for transdermal system}

Transdermal systems are based on the adhesion of the system containing the active ingredient onto the intact skin and the transfer of the dissolved active ingredient through the skin. The limiting factor for the velocity of transdermal absorption is most frequently the thin membrane or a polymeric matrix structure. To fulfil the necessary precondition of the barrier principle as the controlling system of transdermal absorption, the velocity of permeation through the membrane or matrix must be lower than the velocity of penetration into the skin structures. Plasticizers are of extraordinary importance as they ensure not only suitable mechanical properties, in particular flexibility of the system, but also in connection with a decreased value of $\mathrm{T}_{\mathrm{g}}$ increase the diffusivity of polymers.

In the development of a suitable membrane for transdermal use, cellulose acetate casted from a chloroform solution was used. The polymer was plasticized with dibutyl phthalate, polyethylene glycol 600 and propylene glycol in a concentration of $40 \%$. The prepared membranes were characterized from the standpoint of mechanical properties, transfer of water vapours and permeability of diltiazem hydrochloride and indomethacin. Permeability of the active ingredient was the highest with the use of polyethylene glycol as the plasticizer, the lowest in the case of dibutyl phthalate (Rao \& Diwan, 1997). The plasticizer of membranes from cellulose acetate was poly(caprolactone triol), and the pore forming agent was water (Meier et al., 2004). On the basis of testing the permeability of paracetamol, water was demonstrated to be a suitable porosigen with a possible regulation of porosity by its concentration, the plasticizer suitably acting as the modulator of permeation of the active ingredient. A combination of these two excipients yielded the membranes whose values of the coefficients of permeation of paracetamol ranged from $10^{-7}$ to $10^{-5} \mathrm{~cm} \mathrm{~s}^{-1}$.

The matrix system from polyvinyl acetate containing polyethylene- 2 oleyl ether as the enhancer of permeation and triethyl citrate as the plasticizer resulted in a significant increase in the bioavailability of the antihistamine drug triprolidine. The effect was demonstrated after the administration of the system to the abdominal rabbit skin (Shin \& Choi, 2005). Roughness, mechanical and adhesive properties of skin patch were studied. An adhesive plaster was prepared from a blend of polyvinyl alcohol and polyvinylpyrrolidon with glycerol or polyethylene glycols 200 or 400 as the plasticizers. The adhesivity of the system was ascertained only in contact with wet surfaces. Glycerol in a concentration of $10 \%$ did not influence the very smooth texture of the surface of the plaster. The effect of the plasticizer was increased with decreasing molecular mass (Gal \& Nussinovitch, 2009). 


\section{Matrix polymeric systems}

Matrix polymeric systems are heterogeneous systems composed of a polymer, plasticizers, other additives and the active ingredient, and they can be porous. They include primarily oral preparations with prolonged or retarded release of the active ingredient, or implants produced by extrusion or hot moulding or compression.

Extrusion is a process of conversion of raw materials to form a product of a uniform shape and density by forcing it through a nozzle under controlled conditions (Breitenbach, 2002). Plasticizers facilitate the manufacture and improve the parameters of preparations such as porosity, tortuosity, mechanical resistance, diffusivity, or compatibility of the components. Hot-melt extrusion, in which it is possible to process materials with higher $T_{g}$ values, is advantageous.

Due to their little volatility, the plasticizers which are in the solid state in room temperature are advantageous. For plasticization of polyacrylate polymers, e.g. matrices from Eudragit RS PO, citric acid, in particular its monohydrate, turned out to be useful. Tensile strength and the elastic modulus were decreased, whereas elongation was increased. The plasticizing effect of citric acid achieved the plateau stage at its $25 \%$ concentration in polyacrylate, i.e. when achieving the solubility value of (Schilling et al., 2007). The continous process of extrusion and subsequent division of the extruded body into tablets was used in the formulation of enterosolvent preparations from the polyacrylate material Eudragit L100-55. Mixtures of two plasticizers, triethyl citrate and citric acid, were employed. Triethyl citrate markedly decreased the $T_{g}$ value and thus decreased the temperatures in the individual zones of the extruder and the pressure during extrusion. The optimal concentration of citric acid was $17 \%$. 5-aminosalicylic acid was employed as the model active ingredient (Andrews et al., 2008).

Subcutaneous implants of a diameter of $1.5 \mathrm{~mm}$ and length of $18 \mathrm{~mm}$ weighing $40 \mathrm{mg}$ containing thermolabile recombinant proteins and peptides were prepared from plasticized poly(lactide-co-glycolide) as the carrier and ethanol as the plasticizer (Mauriac \& Marion, 2006). First, a $10 \%$ solution of the polymer in ethanol was prepared, followed by drying to achieve an ethanol concentration of $20 \%$. The polymer plasticized in such a way was mixed with the unplasticized one and the mixture was extruded at $75^{\circ} \mathrm{C}$. The following step was grinding of the extrudate at -5 to $-10{ }^{\circ} \mathrm{C}$ with an ethanol content of $8 \%$. The active ingredient and other additives were added to the powder and the mixture was extruded at a temperature up to $70^{\circ} \mathrm{C}$. Another example of extremely volatile plasticizer is supercritical carbon dioxide (Lakshman, 2008). This compoud is added to facilitate processing of materials by extrusion method.

Starch is the biomaterial which has excellent parameters from the standpoint of availability, price and biocompatibility. In the presence of water and suitable polar hydrophilic compatible plasticizers during extrusions at temperatures over $100{ }^{\circ} \mathrm{C}$ amylopectin flows and at the same time native starch granules partially melt. The material can have two markedly different values of $\mathrm{T}_{\mathrm{g}}$. Interactions between starch and plasticizers with strong hydrogen bonds (Pushpadass et al., 2008) were demonstrated in it. The use of glycerol in a concentration of $25 \%$ and secondary plasticizers such as stearic acid, sucrose or urea in markedly lower concentrations are advantageous. It thus yields a flexible material suitable as a biodegradable drug carrier. 
The matrix system containing a plasticized polymer can be also prepared by coating the pellets with a plasticized polymer and their subsequent compression to form tablets (Abdul et al., 2010). The use of a plasticizer does not require a curing step, which is heating after preparation. Pellets without a plasticizer are very brittle and break on compression. After an addition of $10 \%$ triethyl citrate to the polymer Kollicoat SR30D (aqueous colloidal dispersion of polyvinyl acetate) the flexibility of the material was dramatically improved (Savicki \& Lunio, 2005).

\section{In situ forming implants}

The classic medicated implants are the bodies of the solid state and of a defined shape, which are administered by an invasive surgical intervention into the muscular or other tissue. Their implantation requires local anaesthesia and a surgical intervention. In situ forming implants (ISFI) are liquid systems with a relatively low viscosity administered by an injection needle or a trocar containing a substance or several substances, which in the site of administration due to the biological environment spontaneously change its or their properties, in particular the mechanical ones. An important parameter is easy elimination capacity of systems based either on their biodegradability or slow dissolution (Hatefi \& Amsden, 2002). The systems contain an active ingredient which is released from such implants in a long-term period, in the order of weeks to months. It thus enhances the effect of active ingredients, with decreased fluctuation of plasma concentrations toxicity is decreased, with decreased frequency of dosing the compliance of the patient is increased. Besides easy administration, an advantage of this relatively new dosage form is its simple manufacture. The systems find their use in human medicine, veterinary medicine (Winzenburg et al., 2004), and tissue engineering (Quaglia, 2008).

ISFI are suitable for both local and systemic administration of substances with antimicrobial activity, antitumor substances, hormones, substances interacting with the immunity system, growth factors, etc. The importance of this mode of administration will be increased with the introduction of other medicinal substances of the protein type, as the structure of the implant can protect these substances against their enzymatic decomposition.

The first system is named Atrigel Technology ${ }^{\circledR}$ and was patented in 1990 (Dunn et al., 1990; Warren et al., 2009). It is based on the administration of solutions of biodegradable polymers into the soft tissue. After administration, the water-soluble solvent is distributed into the surrounding tissue and the polymer is precipitated due to a backflow of aqueous solutions from the biological environment. The development of implants was studied in vivo using a non-invasive ultrasound imaging technique. The release of the active ingredient from implants has been demonstrated to be influenced not only by the composition of the surrounding pathologically changed tissue, but also by the mechanical conditions in it (Patel et al., 2010), and the process of precipitation of the polymer is considerably influenced by its molecular mass (Solorio et al., 2010). A system with continuous release of the immunoenhancer thymosin alpha 1 was constructed by dispersion of chitosan or albumin microparticles with this substance in the poly(lactide-co-glycolide) matrices dissolved in N-methyl-2-pyrrolidone. This achieved thymosin release for a period of 15 to 30 days (Liu et al., 2010).

The problem of the system Atrigel Technology ${ }^{\circledR}$ is the toxicity of solvents and a sudden initial release of a substantial part of the total dose of the contained active ingredient. In 
spite of it, in praxis there are antimicrobial and hormonal preparations based on this principle. The system based on the principle of rapid precipitation of the solutions of the biotechnological copolymer PHB/PHC in different solvents was employed to formulate ISFI of the film type acting preventively against adhesions of the tissues as undesirable phenomena in post-surgical applications (Dai et al., 2009).

Other types of ISFI are three-block copolymers of ABA or BAB types based on the gelation of their solutions after administration due to increased temperatures. Oligomers composed of polyethylene glycol blocks and the blocks of polyesters of aliphatic hydroxy acids are advantageous (Quiao et al, 2007; Tang \& Singh, 2009). An advantage of the system $\operatorname{ReGel}^{\circledR}$ is the absence of toxic organic solvents and a solubilizing potential of the block copolymer. In pharmacotherapeutic praxis the system $\mathrm{ReGel}^{\circledR}$ with paclitaxel called OncoGel ${ }^{\circledR}$ is employed (Matthes et al., 2007; ). For some active ingredients, some polymers and some modes of administration a too intensive burst effect, changes in the velocity of release of the active ingredient, or irritability of the polymer, which in the systems is used in higher concentrations, can occur (Packhaeuser et al., 2004).

Instead of polymer solutions in hydrophilic solvents, hydrophobic solvents of lower concentrations than the polymer concentration can be employed. They are thus the plasticized polymers. The behaviour of the system after its administration into the tissue is different, the system is not distributed into the environment. The polymer and possibly the plasticizer are subject to biodegradation, the mechanism of the release of the active ingredient is due to the enzymatic or hydrolytic destruction of the implant. A sufficiently low viscosity can be achieved, besides the use of the plasticizer, by increasing the temperature of the applied system. The maximal painless temperature in humans is stated as $53{ }^{\circ} \mathrm{C}$, the maximal tolerable temperature without necrotic changes is $60{ }^{\circ} \mathrm{C}$ (Liu \& Wilson, 1998).

The flowable composition relates to a sustained released delivery system with risperidone was patented. It may be injected into the tissue whereupon it coagulates to become the solid or gel, monolitic implant (Dadey, 2010).

An in-situ-hardening paste, containing a biodagradable polymer and water soluble polymeric plasticizer was developed as delivery system for an active agent in the field of tissue regeneration. The hardened paste can be used as bone and cartilage replacement matrix (Hellebrand et. al., 2009).

The following Table 1 presents a survey of hydrophobic plasticizers suitable for ISFI.

\begin{tabular}{|l|c|c|c|}
\hline Substance & Melting point & Boiling point & $\begin{array}{c}\text { Solubility } \\
\text { in water [\%] }\end{array}$ \\
\hline Benzyl alcohol & $-15^{\circ} \mathrm{C}$ & $205^{\circ} \mathrm{C}$ & 4.0 \\
\hline Benzyl benzoate & $70^{\circ} \mathrm{C}$ & $324^{\circ} \mathrm{C}$ & $1.5 \times 10^{-5}$ \\
\hline Ethyl heptanoate & $-66^{\circ} \mathrm{C}$ & $189^{\circ} \mathrm{C}$ & $3.0 \times 10^{-4}$ \\
\hline Propylene carbonate & $-55^{\circ} \mathrm{C}$ & $242^{\circ} \mathrm{C}$ & 17.5 \\
\hline Triacetin & $3{ }^{\circ} \mathrm{C}$ & $258^{\circ} \mathrm{C}$ & 7.0 \\
\hline Triethyl citrate & $-55^{\circ} \mathrm{C}$ & $235^{\circ} \mathrm{C} / 20 \mathrm{kPa}$ & 6.5 \\
\hline
\end{tabular}

Table 1. Characteristics of selected plasticizers with limited miscibility with water. 
ISFI of this type use the protected name Alzamer ${ }^{\circledR}$ Depot technology (Alza Corporation) and are intended for subcutaneous administration. Thanks to the hydrophobic plasticizer, the systems possess a lower speed of degradation with a smaller burst and a slower release of the active ingredient (Matschke et al., 2002). Biocompatibility of plasticizers is higher than in the case of hydrophilic solvents. The advantage of most plasticizers of this type is their low volatility. Proteins and peptides are not dissolved in the systems, their suspensions are chemically very stable (Solanki et al., 2010). For a sufficiently decreased miscibility of ISFI of this type with the surrounding tissue liquid it is necessary to have the solubility of plasticizers in water lower than $7 \%$ (Brodbeck et al., 2000). In situ forming thin membranes were prepared by mixing poly(lactide-co-glycolide) with $10 \%$ polysorbate 80 as the plasticizer (Koocheki et al., 2011).

\section{Plasticized polymeric microparticles}

It is possible to differentiate two types of microparticles on the basis of their supramolecular texture. Microcapsules consist of a central part, which is called the core, and the peripheral part called the wall. The core contains the active ingredient; the wall is composed of the polymer. The microspheres are composed of a blend of a polymer and a suspended or dissolved active ingredient in the whole volume. The purpose of plasticization of polymers as the carriers of active ingredients in the microparticles is the modification of the kinetics of release either by changes in their hydrophilicity or lipophilicity, or a change in the $T_{g}$ value, or a change in crystallinity. Release of active substances connected with these parameters of polymeric materials, and can be influenced by swelling, erosion, desorption, obstructive phenomena, osmotic phenomena, capillarity, etc.

Microspheres from the blends of hydroxypropyl methylcellulose and ethylcellulose with metoprolol were plasticized with diethyl phthalate. With increasing concentration of the active ingredient, the velocity of release was decreased. Microparticles plasticized in a $5 \%$ concentration of the hydrophobic excipient possessed the velocity of release identical with that of the non-plasticized microspheres, an increase of the concentration of the plasticizer from $15 \%$ to $20 \%$ resulted in a significant increase in the velocity of release (Somwanshi et al., 2011). Indomethacin-loaded microspheres from poly(methyl methacrylate) intended for oral administration were prepared. The period of release of the active ingredient from non-plasticized microparticles was $8 \mathrm{~h}$. After addition of triacetin, the release lasted for $24 \mathrm{~h}$. Fourier transform infrared and nuclear magnetic resonance spectra demonstrated an interaction of the hydrogen type bonds between indomethacin and the polymer. No interaction was demonstrated between triacetin and indomethacin or the polymer (Yuksel et al., 2011).

The liquid pharmaceutical formulations for oral administration with modified release of active principle, excluding amoxicillin was patented. Microcapsules prepared by microencapsulation of the active ingredient using proper polymer-plasticizer mixture were homogeneously dispersed into the external liquid phase (Castan et. al, 2011).

In the course of release, the microspheres from poly(DL-lactide) were plasticized with water from the dissolution medium. $T_{g}$ values rapidly decreased. At temperatures higher than $T_{g}$ a rapid erosion of microspheres occurred, whereas at lower temperatures the polymer did not change for the period of the experiment (Aso et al., 1994). The microspheres from poly(L- 
lactide) and poly(lactide-co-glycolide) were obtained. After preparation using a standard solvent evaporation technique after freeze and oven drying these microparticles contained up to $3 \%$ of water. Residual water markedly decreases $\mathrm{T}_{\mathrm{g}}$ values according to GordonTaylor relationship (Passerini \& Craig, 2001).

The microspheres intended for target oriented drug distribution were prepared from poly(lactic-co-glycolic acid) containing the chemotherapeutic agent etoposide in various concentrations. Plasticization with tricaprin in concentrations of $25 \%$ and $50 \%$ significantly increases the velocity of etoposide release in comparison with the microspheres without a plasticizer (Schaefer \& Singh, 2002). The microcapsules containing the active ingredients soluble in water were prepared by the $\mathrm{o} / \mathrm{o} / \mathrm{o}$ emulsion method under the extraction of the solvent. Peanut oil was employed in the middle oily phase of multiple emulsion (Elkharraz et al., 2011). This peanut oil plasticized the internal phase containing a solution of the active ingredient and poly(DL-lactide) or poly(lactide-co-glycolide) .

The velocity of release of the anticancer agent paclitaxel from poly(lactic-co-glycolic) microspheres was increased after addition of $30 \%$ of isopropyl myristate, $70 \%$ of the active ingredient was released within 3 weeks. After an increase in the concentration of the plasticizer to $50 \%$ there was another increase in the velocity of the process. The plasticizer did not influence the course of degradation of polymers. Release of paclitaxel took place by the mechanism of diffusion from minimatrices (Sato et al., 1996). Analogous conclusions were published in a similar case of microspheres with etoposide (Schaefer \& Singh, 2000).

In situ forming microparticle systems are based on the emulsification of the solution of the active ingredient and polymer in the outer oily or aqueous phase. After the application of the emulsion there occurs separation of the solvent to the biological environment and solidification of the system. Besides water-soluble solvents it is possible to use the more hydrophobic, in a limited degree water soluble ones, which act as plasticizers. Myotoxicity of the plasticizers of this type is lower; the following series of decreasing toxicity was found: benzylalcohol $>$ triethyl citrate $>$ triacetin $>$ propylene carbonate $>$ ethyl acetate. Myotoxicity of ethyl acetate was comparable with the isotonic sodium chloride (Rungseevijitprapa et al., 2008).

\section{Bioadesive plasticized polymers}

Plasticized polymers play an unsubstitutable role in the formulation of the bioadhesive drug delivery systems (BDDS). Bioadhesive polymers have been formulated into tablets, patches, or microparticles, typically as a matrix into which the drug is dispersed, or as a barrier through which the drug diffuses (Ahuja et al., 1997).

In most instances bioadhesive formulations are preferred over the conventional dosage forms, because bioadhesion allows the retention of the active substance in the place of application, or even absorption, and thus increases transmucosal fluxes. As mostly the hepatic first-pass metabolism is avoided, drug bioavailability may be enhanced. Target sites for bioadhesive drug delivery include the eye, GIT, oral cavity, nasal cavity, vagina, and cervix. The development of the adhesive dosage forms for controlled drug delivery to or via mucous membranes is of interest with regard to local drug therapy, as well the systemic administration of peptides and other drugs poorly absorbable from the gastrointestinal 
tract. There is an important difference between the technical adhesion and bioadhesion; it is the presence of water, which is necessary for bioadhesion but impedes most technical applications.

Similar to the plasticization mechanism also the mechanism of bioadhesion is usually analysed based on the polymer chains attractive and repulsive forces. Generally, bioadhesion is regarded as a two-step process. The first step is considered to be an interfacial phenomenon influenced by the surface energy effects and spreading process; a second step involves chain entanglement across a large distance, i.e. polymer chains show interdiffusion. Plasticizers can significantly influence both of these mentioned steps.

According to the wetting theory of bioadhesion (Smart, 2005), there is a significant effect of the viscosity of the plasticized polymer on adhesivity. A plasticized polymer due to a lower viscosity has a higher ability to spread onto a surface as a prerequisite for the development of adhesion.

The plasticizer reduces the aggregation process caused by the intermolecular attraction of the polymer, and it results in an increase in bioadhesiveness. The strength of bioadhesion should be sufficient, but not so sharp as to damage the biological tissue in the application site. The molecular weight, solubility parameter and concentration of the plasticizers used play an significant role. Further, a lower molecular weight or a higher concentration of plasticizers might lead to a greater plasticizing action (Qussi, \& Suess, 2006).

Since the strength of adhesion is dependent on the number and type of interfacial interactions, different polymers and the way of their plasticization will exhibit different adhesive properties depending on both the chemical structure and physico-chemical properties of the polymer, as well the plasticizer used. Many approved pharmaceutical excipients, which are well known and widely used, possess bioadhesive properties and are the first choice candidates for the formulation of bioadhesive preparations particularly due to easier registration.

Bioadhesive materials are generally hydrophilic macromolecular compounds that contain numerous hydrogen bond forming groups, notably carboxyl, hydroxyl, amide and amine groups, and will hydrate and swell when placed in contact with an aqueous solution. Most often these materials need to hydrate to become adhesive but overhydration usually results in the formation of a slippery mucilage and loss of the adhesive properties (Peppas \& Sahlin,1996). The invention provides mucoadhesive bioerodible, water soluble carriers for ocular delivery of pharmaceuticals for either systemic or local therapy (Warren et al., 2008).

Plasticizer efficiency in bio/mucoadhesion is negatively influenced by inducing of the drugpolymer interactions. In this case, the drug in BDDS is not only the active ingredient but represents an antiplasticizing additive responsible for the lowering of the adhesion strength.

The triacetin-plasticized Eudragit E can serve as a film-forming material for the selfadhesive drug-loaded film for transdermal application of piroxicam. Piroxicam did not represent only a simple model drug, it acts as an additive by molecularly dispersing it in the Eudragit E film. Drug-polymer interaction occurring between piroxicam and the Eudragit E film might be responsible for a decrease in adhesion strength. 
In order to improve the flexibility and adhesiveness of the drug-loaded Eudragit E film plasticized with triacetin, secondary plasticizer can be supplemented. Polyethylene glycol 200, propylene glycol, diethyl phthalate, and oleic acid can serve as the secondary plasticizer to improve adhesion (Lin, et al., 1991, 1995).

The adhesive properties were revealed in plasticized star-like branched terpolymers of dipentaeythritol, D,L-lactic acid and glycolic acids, where dipentaerythritol in concentration $3 \%, 5 \%$, or $8 \%$ as the branching agent was used in the synthesis by polycondenzation. The common plasticizer, triethyl citrate, as well the non-traditional plasticizers methyl salicylate, ethyl salicylate, hexyl salicylate, and ethyl pyruvate were used (Fig. 1). These multifunctional plasticizers can serve not only as plasticizers, but potentially pharmacodynamic efficient ingredients.

Presently, there is still no universal test method for bioadhesion measurement. Tensile testing systems are the most widely used in-vitro method for assessing the strength of the bioadhesive interactions. The instrumental variables such as contact force, contact time and speed of withdrawal of probe from the substrate can affect the results of the adhesion measurements.

The adhesiveness of the plasticized branched oligoesters was measured as the maximal force needed for the detachment of the adhesive material from the substrate, using the material testing machine Zwick/Roel T1-FR050TH.A1K (Snejdrova \& Dittrich, 2009). The porcine stomach mucin gel served as a model substrate. All the plasticizers used provide high effectiveness in viscosity lowering, and thus a perfect spreading of the adhesive material on the contact surface as the prerequisite for good adhesion. Sufficient bioadhesion force was revealed in the wide range of dynamic viscosity (Fig. 2) (Snejdrova \& Dittrich, 2008).

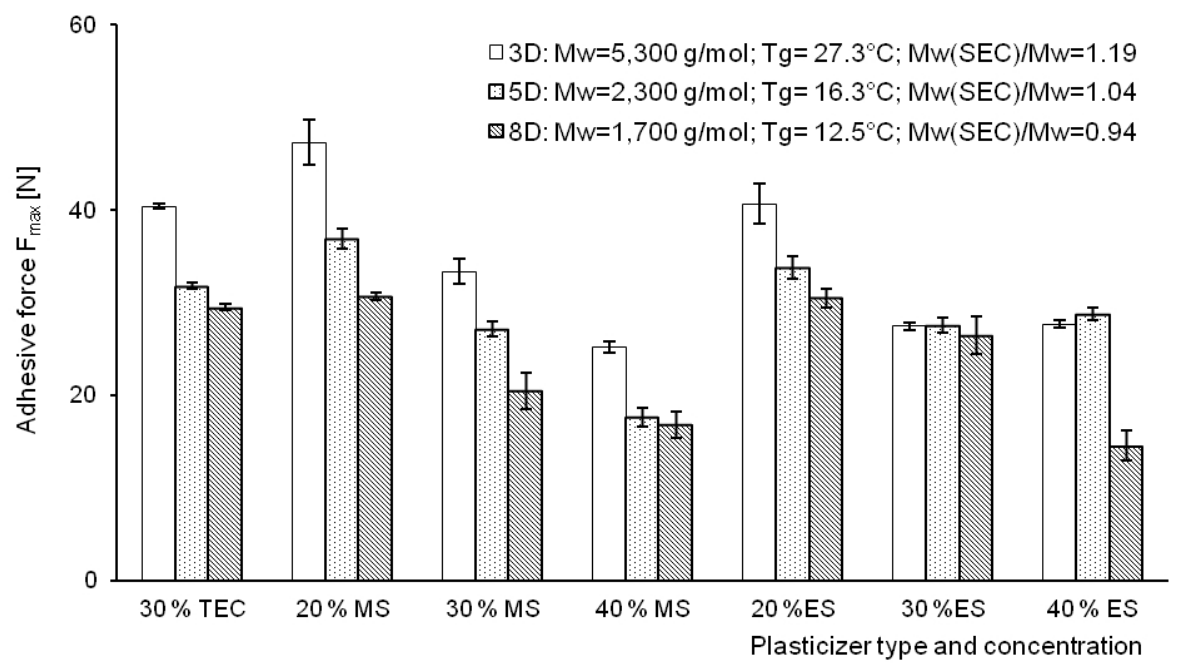

Fig. 1. Adhesiveness of branched oligoester carriers of the drug influenced by plasticizer type and concentration: triethyl citrate (TEC), methyl salicylate (MS), ethyl salicylate (ES). 


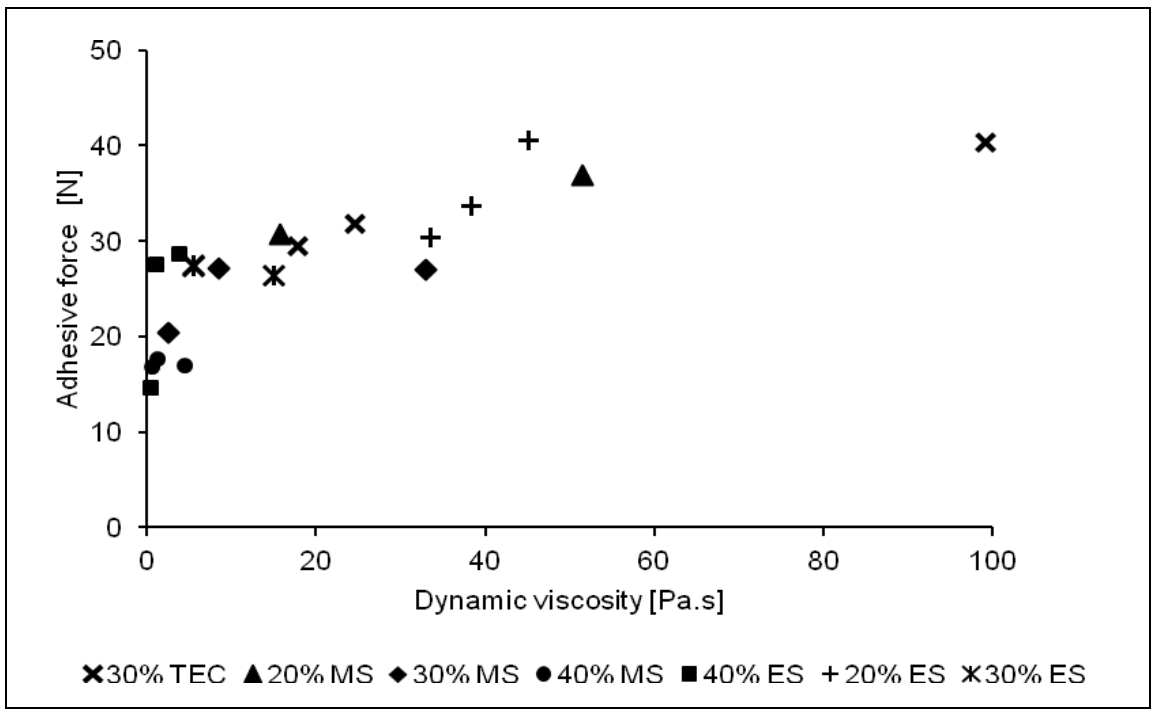

Fig. 2. Relation between viscosity and adhesivity of the branched oligoester carriers plasticized by various type and concentration of the plasticizers (triethyl citrate (TEC), methyl salicylate (MS), ethyl salicylate (ES).

\section{Conclusion}

The plasticization of polymers used in pharmaceutical technology can solve a lot of problems during the dosage forms formulation and can improve the quality of the final polymeric drug delivery system. The processing disadvantages can be thus overcome, or even a new technology can be enabled. The products of new quality are obtained by film coating of tablet with the thin layer of a plasticized polymer. The conventional film coating polymers mask the unpleasant organoleptic qualities of drug incorporated within the solid dosage form and protect the active drug substance from exposure to light, atmospheric moisture and oxygen. The functional coating polymers are used to modify the drug release profile, including the delayed release and sustained release. The membranes plasticized with suitable additive reaches the optimal parameters of permeability combined with the required drug release profile. Thanks to significant decrease of viscosity using the plasticizers, the in situ forming implants can be formulated and administered by an injection needle or a trocar. Multiparticulate dosage forms after incorporation of the proper plasticizer dispose of increased bioavailability.

Plasticized polymers play the unsubstitutable role in the formulation of the bioadhesive drug delivery systems. The adhesive properties were revealed in plasticized star-like branched terpolymers of dipentaeythritol, D,L-lactic acid and glycolic acid. The multifunctional plasticizers methyl salicylate, ethyl salicylate, hexyl salicylate, and ethyl pyruvate can serve not only as plasticizers, but potentially also as pharmacodynamic efficient ingredients. In accordance with the spreading theory of bioadhesion, the decrease in viscosity resulted in improving of the bioadhesivity after addition of these plasticizers. 


\begin{tabular}{|c|c|c|}
\hline $\begin{array}{l}\text { Pharmaceutically used } \\
\text { polymer }\end{array}$ & Plasticizer & Applied as \\
\hline $\begin{array}{l}\text { Cellulose nitrate } \\
(\text {,collodion") }\end{array}$ & castor oil & $\begin{array}{l}\text { historically the first } \\
\text { plasticized polymer } \\
\text { used as a medicinal } \\
\text { preparation } \\
\text { (wounds covering) }\end{array}$ \\
\hline PVC & $\begin{array}{l}\text { di(2-ethylhexyl) phthalate, } \\
\text { diisononyl phthalate, } \\
\text { diisodecyl phthalate, } \\
\text { epoxidized triglyceride, } \\
\text { vegetable oils from soybean oil, } \\
\text { linseed oil, castor oil, } \\
\text { sunflower oil, fatty acid esters } \\
\end{array}$ & $\begin{array}{l}\text { medical devices } \\
\text { (bags, catheters, } \\
\text { gloves, intravenous } \\
\text { fluid containers, blood } \\
\text { bags, medical tubings) }\end{array}$ \\
\hline Ethyl cellulose & dibutyl sebacate & $\begin{array}{l}\text { coatings } \\
\text { free membranes }\end{array}$ \\
\hline Cellulose acetate & $\begin{array}{l}\text { dibutyl phthalate, PEG 600, } \\
\text { propylene glycol, } \\
\text { poly(caprolactone triol) }\end{array}$ & $\begin{array}{l}\text { polymeric membranes } \\
\text { for transdermal } \\
\text { system }\end{array}$ \\
\hline $\begin{array}{l}\text { Blends of hydroxypropyl } \\
\text { methylcellulose and } \\
\text { ethylcellulose }\end{array}$ & diethyl phthalate & microparticles \\
\hline $\begin{array}{l}\text { Cellulose acetate phthalate } \\
\text { Cellulose acetate trimellitate } \\
\text { Hydroxypropyl } \\
\text { methylcellulose phthalate } \\
\text { Polyvinyl acetate phthalate } \\
\text { Shellac }\end{array}$ & $\begin{array}{l}\text { triacetin, acetylated monoglyceride, } \\
\text { diethyl phthalate }\end{array}$ & $\begin{array}{l}\text { enteric or colonic drug } \\
\text { delivery }\end{array}$ \\
\hline $\begin{array}{l}\text { Hydroxypropyl } \\
\text { methylcellulose acetate } \\
\text { succinate }\end{array}$ & $\begin{array}{l}\text { triethyl citrate, triacetin, } \\
\text { acetyltriethyl citrate }\end{array}$ & $\begin{array}{l}\text { press-coated tablets } \\
\text { for colon targeting }\end{array}$ \\
\hline $\begin{array}{l}\text { Blends of ethyl cellulose and } \\
\text { Eudragit }{ }^{\circledR} \text { L }\end{array}$ & dibutyl sebacate & enteric film coatings \\
\hline $\begin{array}{l}\text { Chitosan salts } \\
\text { (chloride, lactate, gluconate) }\end{array}$ & $\begin{array}{l}\text { glycerol, ethylenglycol, } \\
\text { propylenglycol, PEGs }\end{array}$ & free membrane \\
\hline $\begin{array}{l}\text { Blend of native rice starch } \\
\text { and chitosan }\end{array}$ & sorbitol, glycerol, PEG 400 & free membrane \\
\hline $\begin{array}{l}\text { Thermoplastic starch } \\
\text { Amylose } \\
\text { Cassava starch }\end{array}$ & $\begin{array}{l}\text { polyhydric alcohols } \\
\text { (glycerol, xylitol, sorbitol), } \\
\text { secondary plasticizers } \\
\text { (stearic acid, sucrose, urea) }\end{array}$ & polymeric matrices \\
\hline Gelatin & $\begin{array}{l}\text { glycerol, sorbitol, mannitol, sucrose, } \\
\text { citric acid, tartaric acid, maleic acid, } \\
\text { PEGs }\end{array}$ & free membranes \\
\hline
\end{tabular}




\begin{tabular}{|c|c|c|}
\hline $\begin{array}{l}\text { Pharmaceutically used } \\
\text { polymer }\end{array}$ & Plasticizer & Applied as \\
\hline $\begin{array}{l}\text { Whey protein } \\
\text { Sunflower protein }\end{array}$ & $\begin{array}{l}\text { triethyl citrate, tributyl citrate, } \\
\text { acetyl triethyl citrate, acetyl tributyl } \\
\text { citrate, glycerol, ethylene glycol, } \\
\text { propylene glycol, PEGs }\end{array}$ & particulate systems \\
\hline $\begin{array}{l}\text { Poly(lactic acid) } \\
\text { Poly(lactide-co-glycolide) }\end{array}$ & $\begin{array}{l}\text { oligoesters or low-molecular } \\
\text { polyesters, polyesteramides, } \\
\text { PEGs, polypropylene glycol, } \\
\text { blend of triacetin and oligomeric } \\
\text { poly(1,3-butanediol), } \\
\text { active ingredients (ibuprofen, } \\
\text { theophylline, salts of metoprolol } \\
\text { and chlorpheniramine), } \\
\text { ethanol, polysorbate } 80, \\
\text { water, tricaprin, peanut oil, } \\
\text { isopropyl myristate }\end{array}$ & $\begin{array}{l}\text { free membranes } \\
\text { polymeric matrices } \\
\text { in situ forming } \\
\text { systems } \\
\text { microparticles }\end{array}$ \\
\hline $\begin{array}{l}\text { Star-like branched } \\
\text { terpolymers } \\
\text { of dipentaeythritol, D,L-lactic } \\
\text { acid and glycolic acids } \\
\end{array}$ & $\begin{array}{l}\text { triethyl citrate, methyl salicylate, } \\
\text { ethyl salicylate, hexyl salicylate, } \\
\text { ethyl pyruvate }\end{array}$ & $\begin{array}{l}\text { bioadhesive drug } \\
\text { delivery systems }\end{array}$ \\
\hline $\begin{array}{l}\text { Copolymers of methacrylate } \\
\text { esters ammoniated } \\
\text { (Eudragit }{ }^{\circledR} \text { E grades) }\end{array}$ & $\begin{array}{l}\text { tributyl citrate, triacetin, PEG 200, } \\
\text { secondary plasticizer (propylene } \\
\text { glycol, diethyl phthalate, oleic acid) }\end{array}$ & $\begin{array}{l}\text { moisture protection } \\
\text { and odor/taste } \\
\text { masking coatings } \\
\text { bioadhesive drug } \\
\text { delivery systems }\end{array}$ \\
\hline $\begin{array}{l}\text { Copolymers of ethyl acrylate } \\
\text { and methyl methacrylate } \\
\text { (Eudragit }{ }^{\circledR} \text { RL and RS grades) }\end{array}$ & $\begin{array}{l}\text { water (relative humidity), citric acid } \\
\text { monohydrate, active ingredients } \\
\text { (metoprolol tartrate, } \\
\text { chlorpheniramine maleate), } \\
\text { auxiliary compounds (surfactants, } \\
\text { preservatives- methylparaben, } \\
\text { solvents, cosolvents, desolvating } \\
\text { and coacervating agents) }\end{array}$ & $\begin{array}{l}\text { time-controlled drug } \\
\text { release } \\
\text { polymeric matrices }\end{array}$ \\
\hline Poly(methyl methacrylate) & $\begin{array}{l}\text { Triacetin, supercritical carbon } \\
\text { dioxide, dibutyl phthalate }\end{array}$ & $\begin{array}{l}\text { microparticles } \\
\text { intraocular lenses } \\
\text { hard contact lenses } \\
\end{array}$ \\
\hline $\begin{array}{l}\text { Blend of polyvinyl alcohol and } \\
\text { polyvinylpyrrolidon }\end{array}$ & glycerol, PEG 200 or 400 & $\begin{array}{l}\text { polymeric membranes } \\
\text { for transdermal } \\
\text { system }\end{array}$ \\
\hline $\begin{array}{l}\text { Kollicoat SR30D (aqueous } \\
\text { colloidal dispersion of PVA) }\end{array}$ & triethyl citrate & polymeric matrices \\
\hline Various non-soluble polymers & $\begin{array}{l}\text { benzyl alcohol, benzyl benzoate, } \\
\text { ethyl heptanoate, propylene } \\
\text { carbonate, triacetin, triethyl citrate }\end{array}$ & in situ implants \\
\hline
\end{tabular}

Table 2. List of plasticized polymers reviewed in presented chapter. 


\section{References}

Abdul, S., Chandewar, A.V. \& Jaiswal, S.B. (2010). A flexible technology for modified-release drugs: Multiple-unit pellet system (MUPS). Journal of Controlled Release, Vol.147, No.1, (October 2010), pp. 2-16, ISSN 0168-3659

Ahuja, A., Khar, R. P. \& Ali, J. (1997). Mucoadhesive Drug Delivery System. Drug Development E Industrial Pharmacy, Vol.23, No.5, (January 1997), pp. 489 - 515, ISSN 1520-5762

Amighi, K. \& Moes, A. (1996). Influence of plasticizer concentration and storage conditions on the drug release rate from Eudragit ${ }^{\circledR}$ RS 30 D film-coated sustained-release theophylline pellets. European Journal of Pharmaceutics and Biopharmaceutics, Vol.42, No.1, pp. 29-35. ISSN 0939-6411

Andreucatti, C., Carvalho, R.A. \& Grosso, C.R.F. (2009). Effect of hydrophobic plasticizers on functional properties of gelatin-based films. Food Research International, Vol.42, No.8, (October 1994), pp. 1113-1121, ISSN 0963-9969

Andrews, G.P., Jones, D.S., Diak, O.A., McCoy, C.P., Watts, A.B. \& McGinity, J.W. (2008). The manufacture and characterization of hot-melt extruded enteric tablets. European Journal of Pharmaceutics and Biopharmaceutics, Vol.69, No.1, (May 2008), pp. 264-273, ISSN 0939-6411

Arwidsson, H., Hjelstuen, O., Ingason, D. \& Graffner, C. (1991). Properties of ethyl cellulose films for extended release. Part 2. Influence of plasticizer content and coalescence conditions when using aqueous dispersions, Acta Pharmaceutica Nordica, Vol.3, No.2, pp. 65-70, ISSN 1100-1801

Aso, Y., Yoshioka, S., Po, L.W. \& Terao, T. (1994). Effect of temperature on mechanisms of drug release and matrix degradation of poly(DL-lactide) microspheres. Journal of Controlled Release, Vol.31, No.1, (August 1994), pp. 33 - 39, ISSN 0168-3659

Bergo, P. \& Sobral, P.J.A. (2007) Effects of plasticizer on physical properties of pigskin gelatin films. Food Hydrocolloids, Vol. 21, No.8, (December 2007), pp. 1285-1289, ISSN 0268.005X

Bodmeier, R. \& Paeratakul, O. (1992). Leaching of water-soluble plasticizers from polymeric films prepared from aqueous colloidal polymer dispersions. Drug Delivery and Industrial Pharmacy, Vol.18, No.17, (January 1992), pp. 1865-1882, ISSN 1520-5762

Breitenbach, J. (2002). Melt extrusion: from process to drug delivery technology. European Journal of Pharmaceutics and Biopharmaceutics, Vol.54, No.2, (September 2002), pp. 107-117, ISSN 0939-6411

Brodbeck, K.V., Gaynor-Duarte, A.T. \& Shen, T.I. (2004). Gel compositions and methods, US Pat. No. 61032000 (March 21, 2000)

Castan, C., Guimberteau, F. \& Meyrueix, R. (2011). Oral pharmaceutical formulation in the form of aqueous suspension of microcapsules for modified release of amoxicillin. US Pat. No. 7,910, 133 B2 (May 25, 2006)

Dadey, E. (2010). Sustained delivery formulations of risperidone compounds. US Pat. Appl. No. 20100266655 (October 21, 2010)

Dai, Z.W., Zou, X.H. \& Chen, G.Q. (2009). Poly(3-hydroxybutyrate-co-3-hydroxyhexanoate) as an injectable implant system for preventive of post-surgical tissue adhesion. Biomaterials, Vol.30, No.17, (June 2009), pp. 3075-3083, ISSN 0142-9612

Dunn, R.L., English, P., Cowsar, D.R. \& Vanderbilt, P. (1990). Biodegradable in-situ forming implants and methods of producing the same. US Pat. No. 4938763 (June 03, 1990) 
Fedorko, P., Djurado, D., Trznadel M., Dufour B., Rannou P. \& Travers, J.P. (2003). Insulator-metal transition in polyaniline induced by plasticizers. Synthetic Metals, Vol.135-136, (April 2003), pp. 327-8, ISSN 0379-6779

Felton, L.A. \& McGinity, J.W. (1997). Influence of plasticizers on the adhesive properties of an acrylic resin copolymer to hydrophilic and hydrophobic tablet compacts. International Journal of Pharmaceutics, Vol.154, No.2, (August 1997), pp. 167-178, ISSN 0378-5173

Felton, L.A. \& McGinity, J.W. (1999). Adhesion of polymeric films to pharmaceutical solids. European Journal of Pharmaceutics and Biopharmaceutics, Vol.47, No.1, (January 1999), pp. 3-14, ISSN 0939-6411

Felton, L.A., McGinity, J.W. (1996). Influence of tablet hardness and hydrophobicity on the adhesive properties of an acrylic resin copolymer. Pharmaceutical Development $\mathcal{E}$ Technology, Vol.1, No.4, (January 1996). pp. 381-389, ISSN 1083-7450

Fukui, E., Miyamura, N., Yoneyama, T. \& Kobayashi, M. (2001). Drug release from and mechanical properties of press-coated tablets with hydroxypropylmethylcellulose acetate succinate and plasticizers in the outer shell. International Journal of Pharmaceutics, Vol.217, No.1-2, (April 2001), pp. 33-43, ISSN 0378-5173

Gal, A. \& Nussinovich, A. (2009). Plasticizers in the manufacture of novel skin-bioadhesive patches. International Journal of Pharmaceutics, Vol.370, No.1-2, (March 2009), pp. 103-109, ISSN 0378-5173

Gutierrez-Rocca, J.C \& McGinity, J.W. (1994). Infuence of water soluble and insoluble plasticizers on the physical and mechanical properties of acrylic resin copolymers. International Journal of Pharmaceutics, Vol.103, No.3, (March 1994), pp. 293-301, ISSN 0378-5173

Hatefi, A. \& Amsden, B. (2002). Biodegradable injectable in situ forming drug delivery systems. Journal of Controlled Release, Vol.80, No.1-3, (April 2002), pp. 9-28, ISSN 0168-3659

Hellebrand, K., Seidler, M., Schütz, A., Pompe, C. \& Friess, W. (2009). In situ hardening paste, its manufacturing and use. US Pat. Appl. No. 20090048145 (February 19, 2009)

Johnson, K., Hathaway, R., Leung, P. \& Franz, R. (1991). Effect of triacetin and polyethylene glycol 400 on some physical properties of hydroxypropyl methycellulose free films. International Journal of Pharmaceutics, Vol.73, No.3, (July 1991), pp. 197-208, ISSN 0378-5173

Kangarlou, S.; Haririan, I. \& Gholipour, Y. (2008). Physico-mechanical analysis of free ethyl cellulose films comprised with novel plasticizers of vitamin resources. International Journal of Pharmaceutics, Vol.356, No.1-2, (May 2008), pp. 153-166, ISSN 0378-5173

Lakshman, J.P. (2008). Process for making pharmaceutical compositions with a transient plasticizer. US Pat. Appl. No. 20080280999 (November 13, 2008)

Lecomte, F., Siepmann, J., Walther, M., MacRae, R.J. \& Bodmeier, R. (2004). Polymer blends used for the aqueous coating of solid dosage forms: importance of the type of plasticizer. Journal of Controlled Release, Vol. 99, No.1, (September 2004) pp. 1- 13, ISSN 0168-3659

Lehmann, K. (1992). Microcapsules and Nanoparticles in Medicine and Pharmacy, CRC Press, ISBN 0-8493-6986-X, Boca Raton, Florida 
Lin, S.Y., Chau-Jen Lee, Ch.J. \& Lin, Y.Y. (1995). Drug-polymer interaction affecting the mechanical properties, adhesion strength and release kinetics of piroxicam-loaded Eudragit E films plasticized with different plasticizers. Journal of Controlled Release, Vol.33, No.3, (March 1995), pp. 375-381, ISSN 0168-3659

Lin, S.Y., Lee, Ch.J. \& Lin., Y.Y. (1991). The effect of plasticizers on compatibility, mechanical properties, and adhesion strength of drug-free Eudragit E films. Pharmaceutical Research, Vol.8, No.9, (September 1991), pp. 1137-1143, ISSN 1573-904X

Liu, F. \& Wilson, B. C. (1998) Hyperthermia and photodynamic therapy, in: Tannock, I., Hill, R.P. (eds.), Basic Science of Oncology, McGraw-Hill, New York, 1998, pp. 443 - 453, ISBN 0071053166

Liu, Q., Zhang, H., Zhou, G., Xie, S., Zou, H., Yu, Y., Li, G., Sun, D., Zhang, G., Lu, Y. \& Zhong, Y. (2010). In vitro and in vivo study of thymosin alpha 1 biodegradable in situ forming poly(lactide-co-glycolide) implants. International Journal of Pharmaceutics, 397, No.1-2, (September 2010), pp. 122-129, ISSN 0378-5173

Marques, M.R.C., Cole, E., Kruep, D., Gray, V., Murachanian, D., Brown, W.E. \& Giancaspro, G.I. (2009). Liquid-filled gelatin capsules. Pharmacopoeial Forum, Vol. 35, No.4, pp. 1020-1041, USPC

Matschke, Ch., Isele, U., van Hoogevest, P. \& Ffahr, A. (2002). Sustained injectables formed in situ and their potential use for veterinary products. Journal of Controlled Release, Vol.85, No.1-3, (December 2002), pp. 1-15, ISSN 0168-3659

Matthes, K., Mino-Knudson, D.V., Sahani, N., Holalkere, N., Fowers, K.D, Rathi, R. \& Brugge, W.R. (2007). EUS guided injection of paclitaxel (OncoGel) provides therapeutic drug concentrations in the porcine pancreas. Gastrontestinal Endoscopy, Vol.65, No.3, (March 2007), pp. 448-453, ISSN 0016-5107

Mauriac, P. \& Marion, P. (2006). Use of ethanol as plasticizer for preparing subcutaneous implants containing thermolabile active principles dispersed on a plga matrix. US Pat. Appl. No. 20060171987 (July 24, 2004)

Meier, M.M., Kanis, L.A., Solodi, V. (2004). Characterisation and drug-permeation profiles of microporous and dense cellulose acetate membranes: influence of plasticizer and pore forming agent. International Journal of Pharmaceutics, Vol.278, No.1, (June 2004), pp. 99 -110, ISSN 0378-5173

Nair, R., Rajheja, P., Wang, S. \& Pillai, R.S. (2010). Pseudoephedrine pharmaceutical formulations. US Pat. Appl. No. 20100260842 (October 14, 2010)

Orliac, O., Rouilly, A., Silvestre, F. \& Rigal, L. (2003). Effects of various plasticizers on the mechanical properties, water resistance and aging of thermo-moulded films made from sunflower proteins. Industrial Crops and Products, Vol.18, No.2, (September 2003), pp. 91-100, ISSN 0926-6690

Paborji, M. \& Flugel, R.S. (2011). Pharmaceutical formulations for the treatment of overactive bladder. US Pat. Appl. No. 20110244051 (June 10, 2011)

Packenheuser, C.B., Schnieders, J., Oster, C.G. \& Kissel, T. (2004). In situ forming parenteral drug delivery system: an overview. European Journal of Pharmaceutics and Biopharmaceutics, Vol.58, No.2, (September 2004), pp. 445-455, ISSN 0939-6411

Passerini, N. \& Craig, D. Q. M. (2001). An investigation into the effects of residual water on the glass transition termperature of polylactide microspheres using modulated temperature DSC. Journal of Controlled Release, Vol.73, No.1, ( August 1994), pp. 111115, ISSN 0168-3659 
Patel, R.B., Solorio, L., Wu, H., Krupka, T. \& Exner, A.A. (2010). Effect of injection site on in situ implant formation and drug release in vivo. Journal of Controlled Release, Vol.147, No.3, (November 2010), pp. 350-358, ISSN 0168-3659

Peppas, N.A. \& Sahlin, J.J. (1996). Hydrogels as mucoadhesive and bioadhesive materials: a review. Biomaterials, Vol. 17, No.16, 1996, pp. 1553-1561, ISSN 0142-9612

Porter, S.C. (1995). The Coating of Pharmaceutical Dosage Forms, In: The Science and Practice of Pharmacy, J.P. Remington, A.R. Gennaro, (Eds.), 1650-1659, Mack Pub., ISBN 0912734043, Easton, Pensylvania

Pushpadass, H.A., Marx, D.B. \& Hanna, M. A. (2008). Effects of extrusion temperature and plasticizers on the physical and functional properties of starch films. Starch/Stärke, Vol.60, No.10, (October 2008), pp. 527-538, ISSN 1521-379X

Quaglia, F. (2008). Bioinspired tissue engineering: The great promise of protein delivery. International Journal of Pharmaceutics, Vol.364, No.2, (December 2008), pp. 281-297, ISSN 0378-5173

Quiao, M., Chen, D., Hao, T., Zhao, X., Hu, H. \& Ma, X. (2007). Effect of bee venom peptidecopolymer interactions on thermosensitive hydrogel delivery systems. International Journal of Pharmaceutics Vol.345, No.1-2, (December 2007), pp. 116-124, ISSN 03785173

Qussi, B., Suess, W. G. (2006). The Influence of Different Plasticizers and Polymers on the Mechanical and Thermal Properties, Porosity and Drug Permeability of Free Shellac Films. Drug Development E Industrial Pharmacy, Vol.32, No.4, (January 2006), pp. 403 - 412, ISSN 1520-5762

Rao, P.R. \& Divan, P.V. (1997) Permeability studies of cellulose acetate free films for transdermal use: Influence of plasticizers. Pharmaceutica Acta Helvetiae, Vol.72, No.1, (February 1997), pp. 47-51, ISSN 0031-6865

Rowe, R.C. (1977). The adhesion of film coatings to tablet surfaces - the effect of some direct compression excipients and lubricants. Journal of Pharmacy and Pharmacology, Vol.29, No.1, (September 1977), pp. 723-726, ISSN 2042-7158

Rowe, R.C. (1981). The adhesion of film coatings to tablet surfaces - a problem of stress distribution. Journal of Pharmacy and Pharmacology, Vol.33, No.1 (September 1981), pp. 610-612, ISSN 2042-7158.

Rowe, R.C. (1992). Defects in film-coated tablets: Etiology and solutions, In: Advances in Pharmaceutical Sciences, D. Ganderton, T. Jones (Eds.), 65-99, Academic Press, ISBN, New York, USA

Rungseevijitprapa, W., Brazeau, G.A., Simkins, J.W. \& Bodmeier, R. (2008). Myotoxicity studies of $\mathrm{O} / \mathrm{W}$-in situ forming microparticle systems. European Journal of Pharmaceutics and Biopharmaceutics, Vol. 69, No.1 (May 2008) pp. 126 - 133, ISSN 0939-6411

Sato, Y. M., Wang, Y.M., Adachi, I. \& Horikoshi, I. (1996). Pharmacokinetic study of taxolloaded poly(lactic-co-glycolic acid) microspheres containing isopropyl myristate after targeted delivery to the lung in mice. Biological $\mathcal{E}$ Pharmaceutical Bulletin, Vol.19, No.12 (December 1996), ISSN 0918-6158

Sawicki, W. \& Lunio, R. (2005). Compressibility of floating pellets with verapamil hydrochloride coated with dispersion Kollicoat SR 30 D. European Journal of Pharmaceutics and Biopharmaceutics, Vol.60, No.1 (May 2005), pp.153 - 158, ISSN 0939-6411 
Shin, S.-Ch. \& Choi, J.-S. (2005). Enhanced efficacy of triprolidine by transdermal application of the EVA matrix system in rabbits and rats. European Journal of Pharmaceutics and Biopharmaceutics, Vol.61, No. 1-2, (September 2005), pp.14-19, ISSN 0939-6411

Schaefer, M. J. \& Singh, J. (2000). Effect of isopropyl myristic acid ester on the physical characteristics and in vitro release of etoposide from PLGA microspheres. AAPS PharmSciTech, Vol.1, No.4, Article 32 (November 2000), ISSN 1530-9932

Schaefer, M. J. \& Singh, J. (2002). Effect of tricaprin on the physical characteristic and in vitro release of etoposide from PLGA microspheres. Biomaterials, Vol.23, No.16 (August 2002), pp. 3465 - 3471, ISSN 0142-9612

Schilling, S.U., Shah, N.H., Malick, A.W., Infeld, M.H. \& McGinity, J.W. (2007). Citric acid as a solid-state plasticizer for Eudragit RS PO. Journal of Pharmacy and Pharmacology, Vol.69, No.11, (November 2007), pp. 1493-1500, ISSN 0022-3573

Siepmann, J., Lecomte, F. \& Bodmeier, R. (1999). Diffusion-controlled drug delivery systems: calculation of the required composition to achieve desired release profiles. Journal of Controlled Release, Vol.60, No.3, (June 1999), pp. 379-389., ISSN 0168-3659

Skultety, P.F. \& Sims, S.M. (1987). Evaluation of the loss of propylene glycol during aqueous film coating. Drug Delivery and Industrial Pharmacy, Vol.13, No.12, (January 1987), pp. 2209-2219, ISSN 1520-5762

Smart, J.D. (2005). The basics and underlying mechanisms of mucoadhesion. Advanced Drug Delivery Reviews. Vol.57, No.11, (November 2005), pp. 1556- 1568, ISSN 0169-409X

Snejdrova, E. \& Dittrich, M. (2009). Adhesivity of branched plasticized oligoesters. Ceska a Slovenska Farmacie, Vol.58, No.5-6, (December 2009), pp. 212 - 215, ISSN 1210-7816

Snejdrova, E. \& Dittrich, M. (2008). The reological properties of plasticized branched oligoesters. Folia Pharmaceutica Universitatis Carolinae, Vol.XXXVII, pp. 21-25, ISSN 1210-9495

Sogol, K. \& Ismaeil, H. (2011). Mechanical influence of static versus dynamic loadings on parametrical analysis of plasticized ethyl cellulose films. International Journal of Pharmaceutics, Vol.408, No.1-2, (April 2011), pp. 1-8, ISSN 0378-5173

Solanki, H.K., Thakkar, J.H. \& Jani, G.K. (2010). Recent advances in implantable drug delivery. International Journal of Pharmaceutical Sciences Review and Research, Vol.4, No.3, Article 028, pp. 168-177, ISSN 0976-044X

Solorio, L., Babin, B.M., Patel, R.b., Mach, J., Azar, N. \& Exner, A.A. (2010). Noninvasive characterisation of in situ forming implants using diagnostic ultrasound. Journal of Controlled Release, Vol.143, No.2, (April 2010), pp. 183-190, ISSN 0168-3659

Somwanshi, S. B., Dolas, R.T., Nikam, V.K., Gaware, V.M., Kotade, K.B., Dhamak, K.B., Khadse, A.N. \& Kashid, V.A. (2011). Effects of drug-polymer ratio and plasticizer concentration on the release of metoprolol polymeric microspheres. International Journal of Pharmaceutical Research and Development, Vol.3, No.3, (May 2011), pp. 139 146, ISSN 0974-9446

Steele, T. W. J., Huang, Ch.L., Widjaja, E., Boey, F.Y.C., Loo, J.S.C. \& Venkatraman, S.S. (2011). The effect of polyetylene glycol structure on paclitaxel drug release and mechanical properties of PLGA thin films. Acta Biomaterialia, Vol.7, No.5, ( May 2011), pp. 1973-1983, ISSN 1742 - 7061

Tang, Y. \& Singh, J. (2009). Biodegradable and biocompatible thermosensitive polymer based injectable implant for controlled release of protein. International Journal of Pharmaceutics, Vol.365, No.1-2, (January 2009), pp. 34-43, ISSN 0378-5173 
Udipi, K. \& Cheng, P. (2004). Plasticized stent coatings. US Pat. Appl. No. 0215336 (October $28,2004)$

Warren, S.L., Dadey, E., Dunn, R.L., Downing, J.M. \& Li, E.Q. (2009). Sustained delivery formulations of octreotide compounds. US Pat. Appl. No. 20090092650 (April 09, 2009)

Warren, S.L., Osborne, D.W. \& Holl, R. (2008). Adhesive bioerodible ocular drug delivery system. US Pat. Appl. No. 20080268021 (October 30, 2008)

Winzenburg, G., Schmidt, C., Fuchs, S. \& Kissel, T. (2004). Biodegradable polymers and their potential use in parenteral veterinary drug delivery systems. Advanced Drug Delivery Reviews, Vol.56, (February 2004), pp. 1453-1466, ISSN 0169-409X

Yuksel, N., Baykara, M., Shirinzade, H. \& Suzen, S. (2011). Investigation of triacetin effect on indomethacin release from poly(methyl methacrylate) microspheres: Evaluation of interactions using FT-IR and NMR spectroscopies. International Journal of Pharmaceutics, Vol.404, No.1-2 (February 2011), pp. 102-109, ISSN 0378-5173

Zhu, Y., Shah, N.H., Malick, A.W., Infeld, M.H. \& McGinity, J.W. (2002). Solid-state plasticization of an acrylic polymer with chlorpheniramine maleate and triethyl citrate. International Journal of Pharmaceutics, Vol. 241, No.2, (July 2002) pp. 301-310, ISSN 0378-5173 


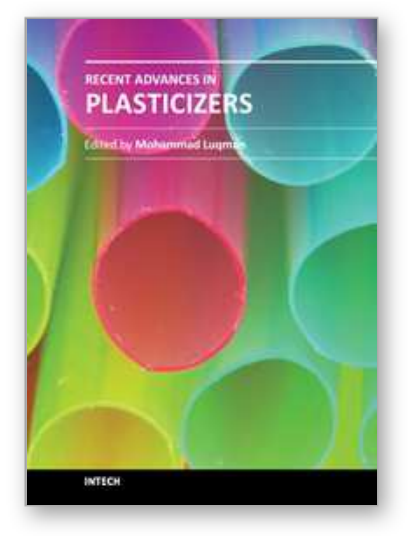

\author{
Recent Advances in Plasticizers \\ Edited by Dr. Mohammad Luqman
}

ISBN 978-953-51-0363-9

Hard cover, 212 pages

Publisher InTech

Published online 21, March, 2012

Published in print edition March, 2012

Plasticizers are used to increase the process-ability, flexibility, and durability of the material, and of course to reduce the cost in many cases. This edition covers introduction and applications of various types of plasticizers including those based on non-toxic and highly effective pyrrolidones, and a new source of Collagen based bioplasticizers that can be obtained from discarded materials from a natural source; Jumbo Squid (Dosidicus gigas). It covers the application of plasticizers in plastic, ion-selective electrode/electrochemical sensor, transdermal drug delivery system, pharmaceutical and environmental sectors. This book can be used as an important reference by graduate students, and researchers, scientists, engineers and industrialists in polymer, electrochemical, pharmaceutical and environmental industries.

\title{
How to reference
}

In order to correctly reference this scholarly work, feel free to copy and paste the following:

Eva Snejdrova and Milan Dittrich (2012). Pharmaceutical Applications of Plasticized Polymers, Recent Advances in Plasticizers, Dr. Mohammad Luqman (Ed.), ISBN: 978-953-51-0363-9, InTech, Available from: http://www.intechopen.com/books/recent-advances-in-plasticizers/pharmaceutical-applications-of-plasticizedpolymers

\section{INTECH}

open science | open minds

\section{InTech Europe}

University Campus STeP Ri Slavka Krautzeka 83/A 51000 Rijeka, Croatia Phone: +385 (51) 770447 Fax: +385 (51) 686166 www.intechopen.com

\author{
InTech China \\ Unit 405, Office Block, Hotel Equatorial Shanghai \\ No.65, Yan An Road (West), Shanghai, 200040, China \\ 中国上海市延安西路65号上海国际贵都大饭店办公楼405单元 \\ Phone: +86-21-62489820 \\ Fax: +86-21-62489821
}


(C) 2012 The Author(s). Licensee IntechOpen. This is an open access article distributed under the terms of the Creative Commons Attribution 3.0 License, which permits unrestricted use, distribution, and reproduction in any medium, provided the original work is properly cited. 